\title{
Linguistic Meaning Versus Pragmatic Meaning
}

\author{
Dr. Mohammad Awwad \\ Assistant Professor Lebanese University Deanship Beirut - Lebanon
}

doi: 10.19044/esj.2017.v13n26p248 URL:http://dx.doi.org/10.19044/esj.2017.v13n26p248

\begin{abstract}
A critical gap between linguistic specifications and context-relevant interpretation has existed ever since linguists sought to investigate meaning. As a matter of fact, English language has gained an unprecedented momentum over the last decades, and the ultimate aim of English language teaching has revolved around fostering the students' ability to communicate proficiently in English. In this realm, much emphasis was given on the development of learners' oral skills; however, those efforts were watered down on the progression of linguistic competence on the expense of communicative competence. In an attempt to bridge this gap, this study adopted Grice's Cooperative Principle (1975) and embodied examples on how participants breach and neglect maxims upon which the Cooperative principle rests. For this aim, the study was carried on 100 English major students enrolled in the TEFL class at the Lebanese University (fifth branch); the investigation was carried over a period of four months in spring 20152016. The results revealed that despite the subjects' adequate linguistic proficiency in English, EFL learners still fall behind attaining pragmatic competence. The study endorses recommendations for EFL learners, teachers, and curriculum designers.
\end{abstract}

Keywords: Pragmatic Meaning, Linguistic Meaning, Semantics,
Competence

\section{Introduction}

Although it seems likely that the majority of English as a foreign language learners (EFL) in the late twentieth century has a great deal of the abstract knowledge of intonation, phonology, syntax, semantics, etc.., many still lack the ability to use language effectively to achieve specific purpose and to understand language in context. This happens despite the fact that EFL learners might produce or consume a bewildering array of conversations. These conversations, in fact, are quite subtle simply because the processes of comprehension and production, involved while communicating, do not underline a clear cut border between what is said and 
what is meant. Consequently, interlocutors do not simply 'decode' an utterance, but arrive at an interpretation through an active process of matching linguistic and non- linguistic features of an utterance at various levels. Here then, studying the invisible meaning and the way we recognize what is meant even when it is not actually said or written, Pragmatics has been posed with a major question of whether the pragmatic competence can ever be taught. In his book, "The study of Meaning”, Yule (2006) considered that communication clearly depends not only on focusing on the conceptual meaning and the relationship between words, but also on recognizing what speakers mean by their utterances. In this respect, the study is meant to reflect a practical investigation on learners' pragmatic competence skills. The Cooperative Principle, first introduced by the American philosopher Grice, was defined as "Make your conversational contribution such as required at the stage of which it occurs, by the accepted purpose or direction of the talk exchange in which you are engaged" (1975, p.45). In this line, the study aims to reveal EFL learners' pragmatic competence and their awareness on the implied meaning in most sociolinguistic educational contexts.

\section{Statement of the Problem}

Though learning a foreign language necessitates the development of learners' speaking proficiency levels, EFL learners seem unable to communicate effectively in English. Even when they do speak in English, EFL learners, even at university level, are neither liable to recognize and interpret the different types of implicatures intended by speakers nor are they capable of transferring their linguistic competence into pragmatic competence. Admitting the turning points made on English language teaching mainly at the writing and reading levels to fostering the students' active construction of meaning rather than responding to what is salient drive educators to wonder whether teaching approaches are on a brink of shift in the speaking skill as well.

What seems of great prominence is the lack of vigilance given to teaching pragmatics principles in EFL contexts. The Cooperative Principle, Speech acts, and politeness principles, indeed, guide people's communication and can be realized by a student- teacher or a studentstudent interaction in oral activities such as situation dialogue, role-play, conversations and hot debates on current issues. Johnson (2000), in this respect, shows that being aware of pragmatics principles can boost student to student interaction in foreign language contexts thus fostering positive opportunities for learners to fortify their communicative competence. 


\section{Purpose of the Study}

This study offers an accessible overview of Pragmatics, as a base for the understanding of Grice's maxims required by all EFL learners, as a general principle, to develop better communication skills. Its significance lies in the sample analysis of conversations of university students who ought to expand their knowledge of Linguistics and gain a more profound understanding of meaning that can be better approached when covering the areas of context, intentions and other nonlinguistic aspects involved in the exploration of the Cooperative principle and implicatures. Moreover, the study can be rendered as a comprehensive tool to investigate the nature of meaning that cannot permanently be exchanged through a mere process of encoding and decoding but goes further beyond to be a 'complicated construction of an abstract component'. One of the main points to be raised is a practical attempt of discovering the very subtle and abstract meaning behind the grammatical structures of syntax. Such attempt entails various aspects like the purpose of communication, the use or the behavior of participants of any conversation, and the linguistic knowledge as interrelated requirements for relating language to the world of experience, society and that of intentions.

\section{Research Questions}

This study deliberately seeks answers for the following questions:

1. To what extent would English Major Students imply messages and why would they tend to?

2. How far might English Major Students be able to identify the maxims followed, violated or breached out, and what variables would impede them from grasping the intended meaning?

\section{Hypotheses}

The study encompasses two hypotheses:

Hypothesis 1: The experimental group students upon which Grice Cooperative principle is investigated and conversational implicatures are introduced are more likely to infer exact meaning by showing significantly high scores in the multiple- choices scenarios in the post test than students with the control group who do not receive that investigational program.

Hypothesis 2: A significant statistical difference will be apparent between the experimental group and the control group in identifying the maxim that was unobserved and the way being breached in the analysis of learners' conversations. 


\section{Theoretical Foundations of Pragmatic Competence}

Studying the invisible meaning and the way humans recognize what is meant even when it is not said or written is inherently correlated with pragmatics. Pragmatics, as a main linguistic principle, has been posed with a major question of whether the pragmatic competence can ever be taught. Although Pragmatics is a relatively new branch of Linguistics, research on it can be dated back to ancient Greece and Rome where the term Pragmaticus was found in late Latin and Pragmaticos in Greek, and they both mean being practical. Modern use and current practice of Pragmatics is credited to the influence of the American Philosophical doctrine of Pragmatism as it occurred in Stanford Encyclopedia of Philosophy (2006).

Pragmatics is a systematic way of explaining language use in context. It seeks to explain aspects of meaning which cannot be found in the plain sense of words or structures, as explained by semantics. As a field of language study, pragmatics is fairly new. Its origins lie in the philosophy of language and the American philosophical school of pragmatism. As a discipline within language science, its roots lie in the work of (Herbert) Paul Grice (1957) on conversational implicature and the cooperative principle, and on the work of Levinson (1983), and Leech (1983) on politeness.

Some linguists, as Geoffrey (2000), consider Pragmatics as the field of inquiry that studies the factors which govern our choice of language in any social interaction and the effect of our choice on others. Geoffrey (2000) expresses that Pragmatics emphasizes what is not explicitly stated and how we interpret utterances in situational contexts.

Levinson (1983) shows that Pragmatics is concerned with the "encoded aspects of context", therefore considering it a theory of language understanding that takes account into consideration, and thereby extending some definitions of Pragmatics that equated it to Semantics. Trask (2007) confirmed this extending showing that Pragmatics can be used in a broader sense in a way where Linguists would regard it as belonging to sociolinguistics. Brisard (2009) renders Pragmatics, as the analysis which straightforwardly corresponds to the challenge of some linguists of how to bring the purpose of communication, the use or the behavior of participants in any conversation and the linguistic knowledge as a whole, altogether, in an interrelated manner. Birner (2012), on his part, foresees that Pragmatics seems more than related with Semantics and Grammar. He acknowledged the deep relation between Pragmatics and Semantics in a sense where the two fields deal with meaning, but still they are distinct. In his "Introduction to Pragmatics", Birner (2012) demonstrates that Semantics provides an understanding of the literal meaning of a word or a sentence as opposed to what might be conveyed in a certain context in pragmatics, and here where things became more challenging. In the attempt of discovering the very 
subtle and abstract meaning, Birner (2012) adds that upon trying to disentangle the two types of meaning from each other, things get considerably more difficult.

Definitions on Pragmatics have been widely generated but most converge in the fact that Pragmatics is all about the meanings between the lexis and the grammar and the phonology. Meanings are implied and the rules being followed are unspoken, unwritten ones. Many linguists agree on the fact that Pragmatics is a way of investigating how sense can be made of certain texts even when, from a semantic viewpoint, the text seems to be either incomplete or to have a different meaning to what is really intended. If we consider a sign seen in children's wear shop window: "Baby Sale- Lots of Bargains." We know without asking that there are no babies for sale and that what is for sale, are items used for babies. Pragmatics allows us to investigate how this "meaning beyond the words" can be understood without ambiguity. The extra meaning is there, not because of the semantic aspect of the words themselves, but because we share certain contextual knowledge with the writer or speaker of the text.

Grice (1975) proposed that in all communication, there are guiding principles that direct conversation. He postulated that contributions in an exchange will most likely not be random and disconnected remarks, but that participants will rather offer an utterance that is related to the purpose or direction of the conversation. Grice (1975) further added implicatures that can be seen as an attempt to build on a common sense view of verbal communication by making it more explicit and exploring its implications. Implicatures are the aspect of meaning that a speaker conveys, implies, or suggests without directly expressing. An implicature can be defined as the proposition inferred from the circumstances of utterances of another proposition rather than its literal meaning. As a technical term, first coined by Grice (1975) in the subfield of Pragmatics in Linguistics, an implicature refers to "what is suggested in an utterance even though neither expressed nor strictly entailed by the utterance" (p.56). There is, thus, an expectation from both the speaker and the hearer that what is said will promote effective and cooperative communication. Grice formulated this expectation as an overarching assumption of cooperation that participants in a conversation will strive to make a contribution that is appropriate and acceptable in terms of the context of the conversation. The Cooperative Principle (CP) requires participants to make their contribution such as is required, at the stage at which it occurs, by the accepted purpose or direction of the talk exchange in which they are engaged" (p.45). Grice, respectively, developed nine maxims classified into four categories or expressed as the four maxims of the CP. Those maxims account for the general standards governing verbal 
communication and make it possible to explain the meaning in a certain utterance. Cutting (2002) summarizes the maxims as follows:

- Quantity :

- Quality: Try to make your contribution one that is true.

- Relation: Be relevant.

- Manner: Be perspicuous. (Grice 1981/1989, p. 273).

\section{Methodology}

\section{Design}

The study has embraced a mixed qualitative- quantitative approach where it sought to analyze answers and responses of participants and examine the social and cultural contexts within which the latter's conversations occurred. The students have had a set of scenarios with multiple choices originally proposed by Grice (1975, p. 53) and Bouton (1988, p. 193-194; 1994, p. 163). Answers on these scenarios were calculated, categorized, and then interpreted to reveal numbers as well as notes on the effectiveness of teaching the $\mathrm{CP}$ and the implicatures as one main aspect of Pragmatics.

\section{Participants}

The sample of the study was comprised of 100 English major students, enrolled at the TEFL course, at the Lebanese University, fifth branch. The participants were divided into two groups, a control group of 50 students who did not benefit from treatment, and an experimental group of 50 students who were exposed to Grice Cooperative Principle and implicatures.

\section{Instruments}

The data for this research was collected through observations and assessments in the form of scenarios with multiple choices extracted from Bouton (1988, 1994, 1999) and Roever (2004, 2005, 2006, 2007) which commenced after the intervention and the discussion of the main principles guiding conversations and oral exchanges and the introduction on implicatures and some reasons behind their appearance. The researcher's role was to quietly listen to conversations at some times, take notes and to interfere in participation, at other instances, to trigger students' efforts in recognizing where, how, and why a certain speaker has implied something but never said and accordingly, raise their awareness towards pragmatics. The instrumentation therefore included a tape recorder which recorded the conversations and the discussions that followed up some scenarios for analysis. The prominent instrument for implementing the study took the form of scenarios with multiple choices where students used to read brief 
conversations and subsequently attempt to recognize the intended meaning of a specific utterance. Each item considered a brief description of a situation and a dialogue between two speakers that contained one or two exchanges with one utterance including an instance of implicature.

\section{Procedure}

The investigation of this topic too was carried out over 15 weeks, particularly four months. The pre-test was carried out to systematically compare and contrast the results with the post test. The first four weeks included shedding light on the maxims upon which Grice Cooperative Principle rests and the implicatures that might appear in the context of oral exchanges leading to a violation for these maxims, and the vital pragmatic bedrock served by such an introduction for a better transactional communication. Another four weeks were devoted to providing students with a practical investigation of what students had learned from the theoretical part in the four weeks earlier via conversational examples arranged as two scenarios with multiple choices per week. Three weeks later, students have had task- oriented chance to apply maxims in their conversations. Eventually, a post test was run on the experimental group and the control group as well to compare and contrast both subjects' performance before and after the treatment period.

\section{Results and Discussion}

Launching from the pre and the post tests, the subjects' results of the two groups were represented in detailed tables and subsequent bar graphs to demonstrate a vivid contrastive variance in the mean before and after the introduction Grice's CP.

Appendix $\mathrm{C}$ shows 8 examples, where students were asked to reflect upon both the first and the last lectures. Each example signified a written scenario with multiple choice questions adopted from Bouton (1988).

The following bar- graphs represent the percentages of the correct responses on the eight questions on the pre and post tests for each of the control group and the experimental group respectively. 


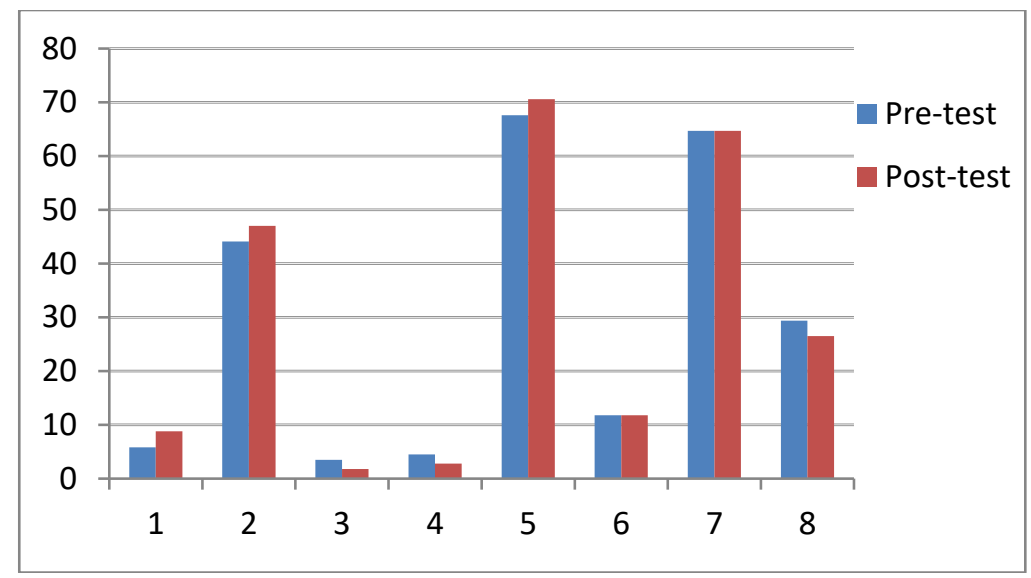

Figure 1: control group

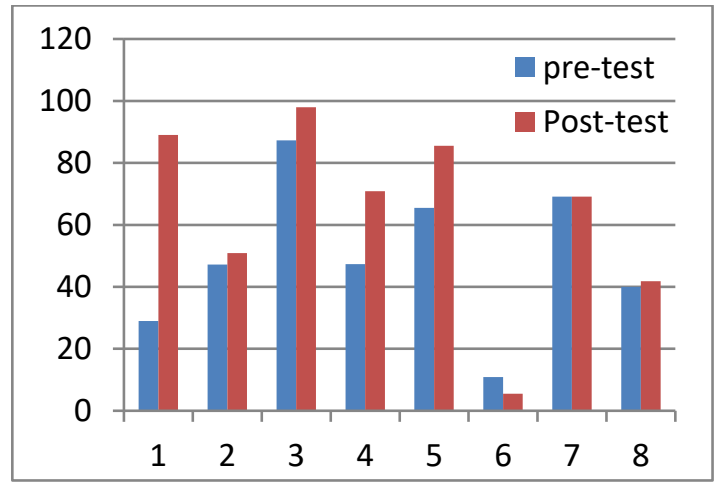

Figure 2: experimental group

In the light of the above, the overall percentage mean of correct responses achieved by control group students, who did not benefit from awareness on Gricean's Cooperative Principles, at the eight scenarios in the implicature test was $41.2 \%$,which is less than the overall average obtained by the experimental group $(63.8 \%)$. Accordingly, hypothesis one is confirmed.

The experimental group students were first introduced to pragmatic concepts, in whole, and then to the Cooperative Principle and the maxims it encompasses. In later sessions, students started to practice the knowledge they gained, and elaborated on the ways where the maxims were not followed (Appendix A). Over time, the participants were allowed to use the diagram representing the different types of breaches of the maxims and therefore identify the maxim being breached, violated, flouted, or infringed. Class discussions were centered on questions like, "Did you understand the conversation, what was the maxim violated, and what do you think was the intended meaning by the second speaker? (Appendix B). Notes were recorded on students' rate of participation and their motivation to share their 
answers, feelings and opinions. The motivation of students belonging to the experimental showed a higher involvement in the investigational program measured by a higher number of occurrences for the violation of the conversational maxims than the control group whose responses and comments were limited.

Table 1 Breached Maxims

\begin{tabular}{|c|c|c|}
\hline Un- observed Maxim & $\begin{array}{c}\text { Number of occurrences by } \\
\text { control group }\end{array}$ & $\begin{array}{c}\text { Number of Occurrences by the } \\
\text { experimental group }\end{array}$ \\
\hline Quality & 3 & 2 \\
\hline Quantity & 9 & 13 \\
\hline Relation & 11 & 11 \\
\hline Manner & 1 & 5 \\
\hline Total & 24 & 31 \\
\hline
\end{tabular}

The total number of occurrences, which students provided as examples showing the failure in observing the maxims of quality, quantity, relation, and manner, was only 24 by the control group, less than that of the experimental group (31 occurrences). The experimental group students were more able to provide examples on conversations where speakers give more or less information than what the situation demands, flouting thereby the maxim of quantity (13 examples). The second rank identified by the participants was the maxim of relation with equal number of occurrences for both groups (11 occurrences). The common in all the suggested conversations was the fact that a violation for the maxim of relation exists mainly when a speaker changes the subject of discussion or fails to address the other's person goal in asking a question. Breaching the maxim of manner occupied the third rank with 5 examples provided by the experimental group, and the forth rank by the control group with just one example. The breaching for the maxim of manner, as elaborated by students comes to occur when a speaker overstates a statement and uses different words with the same meaning repeatedly. The last rank of examples, being the third for the control group, was for the failure in adhering to the maxim of quality by the experimental group with 2 occurrences out of 31 and 3 out of 24 for the control group. This breaching mostly takes place when a speaker says untrue utterances or gets uncertain utterances in conveying the message.

Table 2 Number of Occurrences of Breached Maxims

\begin{tabular}{|c|c|c|}
\hline $\begin{array}{c}\text { Types of Non-Breaching } \\
\text { the Maxims }\end{array}$ & $\begin{array}{c}\text { Number of Occurrences with } \\
\text { the control group }\end{array}$ & $\begin{array}{c}\text { Number of Occurrences with } \\
\text { the experimental group }\end{array}$ \\
\hline Flouting & 13 & 25 \\
\hline Violation & 6 & 7 \\
\hline Infringing & 2 & 2 \\
\hline Opting Out & - & 2 \\
\hline Suspending & - & 41 \\
\hline Total & 21 & 2 \\
\hline
\end{tabular}


The results showed more flouting with the experimental group (25 occurrences) when compared to the control group. This was an indication that students who benefited from the treatment period are more liable to manipulate the linguistic components. Students who were exposed to pragmatic principles can be more flexible in producing utterances with hidden meaning. They have a higher tendency to breach or deviate from the norms to deliver a certain message. An analysis of Table 2 shows that the most frequently form that occurred in the non- observance of maxims is flouting the maxim, with a number of occurrences 13 out of $21(61.9 \%)$ and 25 out of $41(61 \%)$ implying that this type occurs when a speaker fails to observe a maxim at the level of what is said, with a clear intention of generating an implicature. This type is always meant to be noticed and was the dominant type identified by both groups, but clearly more by the experimental group. The second rank of non- observance, being common among the two groups was occupied by the violation of the maxim, which is by contrast to the former, meant to be noticed. Violating the maxim was identified by 6 occurrences for control group, and 7 for experimental group.

All in all, results and notes showed that the experimental group showed more ability in identifying the breaching of maxims and the types of breaching than the control Group. Hence, hypothesis 2, stating that is confirmed.

\section{Conclusion}

A study was conducted on Lebanese University students, English major, fifth branch to investigate the latter's pragmatic competence in oral communication. Via observations, and scenarios, the researcher was able to test the subjects' perception of pragmatic meaning versus linguistic meaning. Seeking the adherence and the violation of the Cooperative Principle itself was an attempt to improve students' competence in verbal communication, avoid intercultural understandings, and foster EFL learners' critical thinking to establish relations, analyze, infer, and in whole, develop their communicative competence which is the heart of oral English Teaching pedagogies. The findings of this study revealed a statistical difference in the average achieved by the experimental group, that benefited from the treatment of pragmatic awareness. The subjects, who were exposed to pragmatic awareness performed better in recognizing where, how, and why a certain speaker has implied something. The recorded conversations and the discussions that followed the scenarios aided in boosting learners' pragmatic competence. The scenarios with multiple choices where students used to read brief conversations and subsequently attempt to recognize the intended meaning of a specific utterance helped in raising learners' attention on the difference between linguistic and pragmatic meaning. Each utterance 
included an instance of implicature that triggered the experimental group to decipher the intended meaning of the utterances.

The findings of the study revealed a statistical difference in the average achieved by the experimental group and that of the control group in the post- test. An increase in the average of the experimental group-leveled students was computed with $14.3 \%$, whereas, the control group witnessed no increase, a constant average in both the pre- and the post tests and a zero\% difference. These findings implied that the linguistic knowledge is initially required to build upon the non-linguistic knowledge and thereby, enable the communicators, and our learners, specifically, to learn about language, the rules governing conversations, and get adapted to using language and changing it according to the needs of the listener and situations.

The study highlighted a strong correlation between the contextual and phonological cues and the meaning interpretation, as inferred by the students' justifications and debates of choosing an answer rather than the other. Commonly realized was the students' demand for someone to read them the scenario so as to facilitate their interpretation of what the speaker might be implying. All students asserted that strong relation, confessing that the utterance would be much more less ambiguous if accompanied with the phonological and paralinguistic features reflected in speech rather than writing.

The study also accounted for the general standards governing verbal communication, the Gricean maxims, and signified how the utterance when providing an ambiguous representation of the thought, nevertheless, expresses a complete and an unambiguous meaning.

\section{Pedagogical Implications}

At the macro level, the purpose of the paper was to reveal the critical consensus on how Pragmatics serves the meaning interpretation and stands along with sociology, psychology, philosophy and anthropology in specifying precisely what it is that being 'transmitted' as a shed lightcontribution to the vast knowledge of meaning. At the micro level, the purpose of the paper has been directed towards considering the normative practices of curriculum designers and teachers who guide or instruct learners that a given term has a particular meaning within a particular academic discipline, and that to conform to that discipline, speakers must say things in that way only. Instead, educators must raise the attention to the meaning of the words and their relation with the pre- and post linguistic structures, the context in which they occur, and some pre-existing knowledge which, in sum, aid in working toward a reasonable interpretation of what the interlocutors intend to convey. The findings presented reveal that Pragmatic 
competence proved to be acquired in a developmental fashion rather than built in, thus it is recommended that teachers master the Gricean maxims, and consequently transfer this knowledge to students.

Curriculum designers are invited, as well, to design materials that help students develop conversational skills, particularly in relation to conversational implicatures. Together with trainers, instructors, and material developers, implicatures can be a part of ESL and EFL programs because the pragmatic norms and principles are indispensable milestone in acquiring a foreign language.

\section{References:}

1. Birner, J. B. (2012), "Introduction to Pragmatics". United States, New Jersey: Wiley- Blackwell.

2. Bouton, L. F. (1988). "A cross-cultural study of ability to interpret implicatures in English." World Englishes, pp. 69-183.

3. Bouton, L.F. (1994). Conversational implicature in the second language: Learned slowly when not deliberately taught. Journal of Pragmatics, pp. 67-157.

4. Bouton, L. F. (1999). Developing non-native speaker skills in interpreting conversational implicatures in English: Explicit teaching can ease the process. In E. Hinkel, (Ed.): Culture in second language teaching and learning (pp. 47-70). Cambridge University Press.

5. Brisard, F. (2009). "Introduction: Meaning and Use in Grammar." Grammar Meaning and Pragmatics, Amsterdam: Benjamins.

6. Cutting, J. (2002). Pragmatics and Discourse: A Resource book for students. London: Routledge.

7. Davis, S. (1991), Pragmatics. A reader, Oxford: Oxford University Press. (Comprehensive collection of fundamental papers in pragmatics).

8. Geoffrey, F. (2000). Linguistic Terms and Concepts, London: Palgrave Macmillan.

9. Grice, H. P. (1957), “Meaning,” Philosophical Review 66, pp. $377-$ 88. United States: Duke University Press.

10. Grice, H. P. (1975). Logic and Conversation, in P. Cole and J. Morgan (Ed.) Pragmatics (Syntax and Semantics). Vol.9, New York: Academic Press.

11. Johnson, K.E. (2000). Understanding Communication in Second Language Classrooms. Beijing: People's Education Press. pp. 13-14.

12. Leech, G. N. (1983). Principles of Pragmatics. London: Longman.

13. Levinson, S. (1983). Pragmatics. Cambridg: Cambridge University Press. 
14. Morris, C. (1938). "Foundations of the theory of signs," in $O$. Neurath, R. Carnap and C. Morris (ed.), International Encyclopedia of Unified Science I, Chicago: University of Chicago Press, pp. 77138. Reprinted in C. Morris 1971, Writings on the general theory of signs, The Hague: Mouton.

15. Roever, C. (2004). Difficulty and practicality in tests of interlanguage pragmatics. In D. Boxer \& A. Cohen (Eds.). Studying speaking to inform language learning pp. 283-301.

16. Stanford Encyclopedia of Philosophy, first published Tue, Nov 28, 2006: substantive revision Mon, Mar 21, 2011. The metaphysics Research Lab, Center for the study of language and information (CSLI), Stanford University library of Congress Catalog Data: ISSN. pp. 1095-5054.

17. Trask, L. B. (2007). Language and Linguistics: The Key Concepts, $2^{\text {nd }}$ ed. By Peter Stockwell. London: Routledge.

18. Yule, G. (2006). The study of Meaning. Cambridge: Cambridge University Press. 
Appendix A: A diagram summarizing the main maxims of $\mathrm{CP}$ as extracted from Murray

(2010)

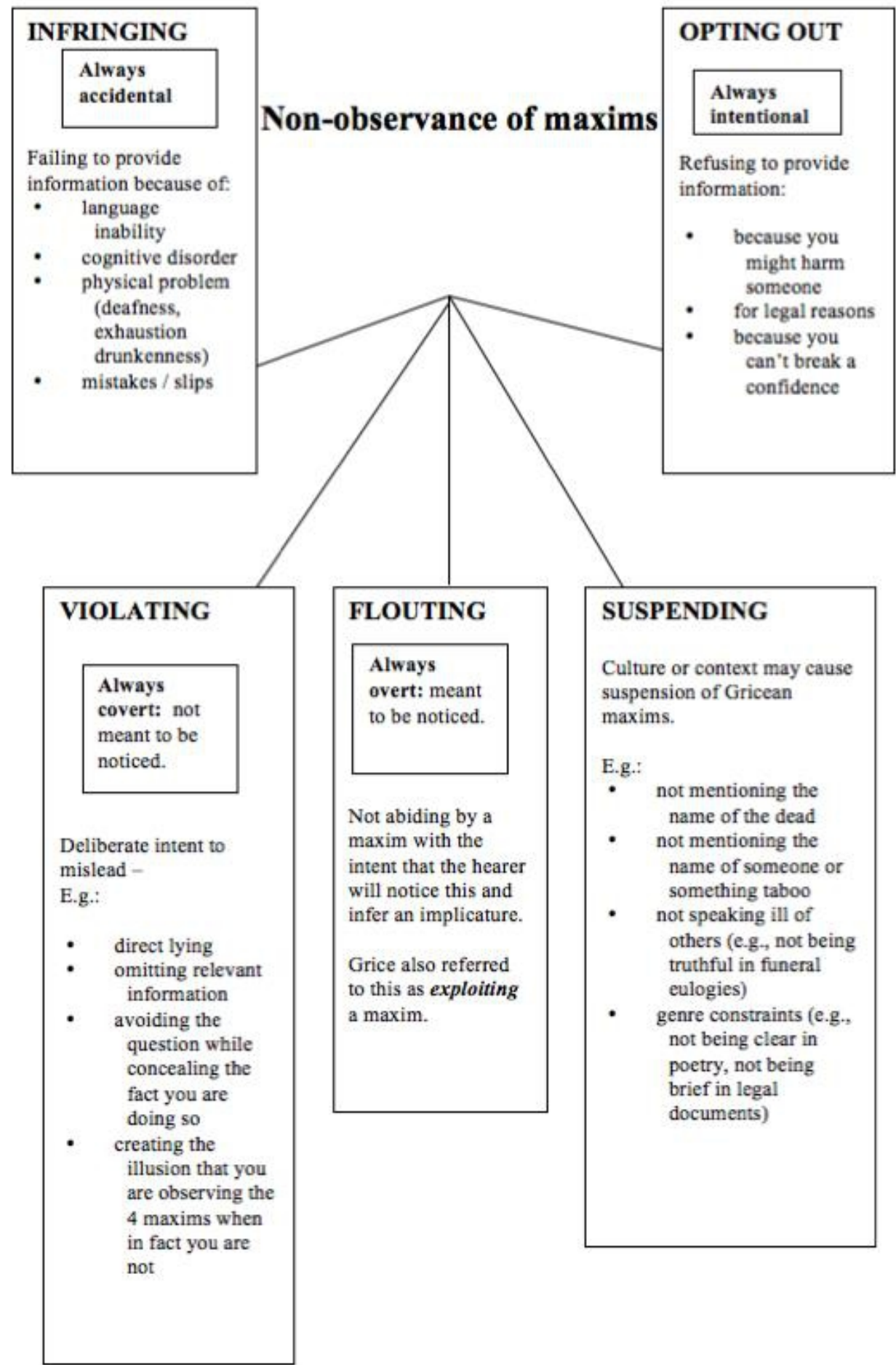




\section{Appendix B}

Sample Task: Implicatures: Saying what you mean or not?

As you go about your life this week, listen to yourself and the people around you. Remark some notes and examples at instances where people do not speak directly, truthfully, clearly, or give the expected amount of information. The examples may be from real life or TV/ movies. Take notes of the context including the speakers, who were they, where were they, and what type of relation exists between them (level of intimacy)? Then recall the exact words that were exchanged, and later reflect by your comments.

Sample answers:

Sample 1:A child was asked by his mom: "what have you done?" he answered: "I have been studying all day long, up till now", at time where the child in fact was the whole day playing, but violated the maxim of quality to avoid unpleasant consequences like punishment.

Sample 2: A roommate asked her friend: "Mirna, where have you been? I searched for you everywhere during the past four hours?" Mirna replied: "I wasn't around. So what's the big deal?" The roommate posed a question to which she needed an answer. What mirna answered in return hasn't lacked the truth, however it was still inadequate. This can be due to the fact that Mirna prefers to refrain from providing her roommate with the answer.

Sample 3: A wife asks: "Darling, what's the story with the new watch on your wrist?" The husband answers: "Oh, this watch you're talking about! I knew it.., I told my boss that my wife would be curious when she sees it. Oh, honey you have no idea how much they're satisfied with my performance, lately! The husband would be better off if he told his wife from the beginning that his boss awarded him a prize. However, he flouts the maxim of quantity and manner to assure his wife that the watch was a gift from a person that she also knew and there's no need for jealousy. This sample would obviously carry a counter interpretation depending on the degree of love and confidence between the wife and her husband.

Sample 4: A teacher says to a student arriving late more than ten minutes to the class meeting: "Wow, you're such a punctual fellow! Welcome to the class." The student answers: "Sorry Sir! It won't happen again." The teacher obviously violates the maxim of quality (being untruthful) to be sarcastic, and likewise, the student seems to notice the purpose behind the teacher's compliment and thus offers an apology.

Sample 5: Moments where little kids pretend feeling hunger and respond, "I'm hungry, or I'm thirsty, Mom.", upon a question, "why haven't you slept yet?" is by analogy, similar to a student's response, "May I go and get some water?" when the teacher asks, "Why didn't you do your homework?" explain children's intention to escape sleeping in the first case, and evade an interrogation in the latter. 


\section{Appendix C: Implicature Test}

Each item consists of a description of the setting and a dialogue that should be imagined to be taking place in different contexts. After each dialogue, there will be a question about what an utterance means. Each question will be followed by four multiple-choice answers. Please choose the answer that seems to best answer the question. Simply imagine that you are present when the dialogue occurs, and choose the answer that is the closest to what you think the utterance means.

Example 1: Bill and Peter have been friends since they were children. They shared together a house when they were students and traveled together after graduation. Now friends have told Bill that they saw Peter dancing with Bill's wife. Bill: "Peter knows how to be a really good friend."

Question: Which of the following best says what Bill meant?

a) Peter is not acting the way a good friend should.

b) Peter and Bill's wife are becoming really good friends while

Bill is away.

c) Peter is a good friend and so Bill can trust him.

d) Nothing should be allowed to interfere with their friendship.

Example 2: Brenda and Sally have lunch every Tuesday. As they meet on this particular day, Brenda stops, twirls like a fashion model, and the following dialogue occurs:

Brenda: I just got a new dress. How do you like it?

Sally: Well, there certainly are a lot of women wearing it this year. When did you get it?

Question: How does Sally like Brenda's new dress?

a) We can tell from what she says.

b) She thinks Brenda has good taste in clothes because she is right in fashion.

c) She likes the dress, but too many women are wearing it.

d) She does not like it.

Example 3: Two roommates are talking. One has just been talking on the telephone to a woman he was going to take to see a play.

David: Darn it! Mandy just broke our date for the play. Now, I have got two tickets for Saturday night and no one to go with.

Mark: Hey, David. Have you ever met my sister? She is coming down to see me this weekend.

David: No, I do not think so, why?

Question: What was Mark's reason for mentioning his sister was coming?

a) Mark is just thinking and ahead to the weekend and cannot remember whether David has met his sister or not.

b) There is nothing Mark can do to help his friend, so he is mentioning a problem of his own. 
c) Mark is suggesting that David take Mark's sister to the play.

Mark wants to be sure that David knows that the woman he is with this weekend is his sister and not a girlfriend.

Example 4: Two roommates are talking about what they are going to do during the summer.

Fran: My mother wants me to stay home and entertain the relatives when they come to visit us at the beach.

Joan: Does a dog have fleas?

Question: How can we best interpret Fran's comment?

a) Fran thinks her relatives are boring.

b) Fran does not have many relatives.

c) Fran does have a lot of relatives.

d) Fran is asking Joan if a dog usually has fleas.

Example 5: Jack is talking to his housemate Sarah about another housemate, Frank.

Jack: 'Do u know where Frank is, Sara?'

Sarah: 'Well, I heard music from his room earlier.'

Question: What does Sara probably mean?

a) Frank forgot to turn the music off.

b) Frank's loud music bothers Sara.

c) Frank is probably in his room.

d) Sara does not know where Frank is.

Example 6: Frank wanted to know what time it was, but he did not have a watch.

Frank: What time is it, Helen?

Helen: The post man has been here.

Frank: Okay. Thanks.

Question: What message does Frank probably get from what Helen says?

a) She is telling him approximately what time it is by telling him that the postman has already been here.

b) By changing the subject, Helen is telling Frank that she does not know what time it is.

c) She thinks that Frank should stop what he is doing and read his mail.

d) Frank will not be able to interpret any message from what Helen says, since she did not answer his question.

Example 7: A manager and his secretary are having a conversation at their office.

Manager: Are you able to find the cards I need for my printer?

Secretary: Well, Yes I do. You should visit that new office building because they have hundreds of printer cards, all you'd ever want to see or buy, and my son works there. You know, he is a very intelligent man. 
Question: What was the secretary intending?

e) She wanted the manager to pay some efforts and check the ink cards by himself.

f) She would like to introduce her son to the manager.

g) She wanted to inform the manager that she could manage all his orders.

h) She wanted to deceive the manager and made him think that she finally got the cards he needed for his printer though, in fact, she had not.

Example 8: At a recent party, there was a lot of singing and piano playing. At one point, Sue played the piano while Mary sang. When Tom asked a friend what Mary had sung, the friend said:

Friend: I am not sure, but Sue was playing "My Wild Irish Rose"

Question: Which of the following is the closest to what Tom's friend meant by this remark?

a) He was only interested in Sue and did not listen to Mary.

b) Mary sang very badly.

c) Mary and Sue were not doing the same song.

d) The song that Mary sang was 'My Wild Irish Rose'.

With full interest to know the choices you had made, all thanks to your contribution. 